\title{
Does Agricultural Mechanization Improve Agriculture Environment Efficiency?-Evidence from China's Planting Industry
}

Yingyu Zhu ( $D$ 13707631938@126.com )

Shenyang Agricultural University https://orcid.org/0000-0002-6380-2081

Yan Zhang

Shenyang Agricultural University https://orcid.org/0000-0002-7156-2954

Huilan Piao

Shenyang Agricultural University

\section{Research Article}

Keywords: Agricultural mechanization, Net carbon sink, Agriculture environment efficiency, Spatial spillover effect, Temporal cumulative effect, Stochastic frontier analysis, Output oriented distance function

Posted Date: December 8th, 2021

DOI: https://doi.org/10.21203/rs.3.rs-1071457/v1

License: (c) (i) This work is licensed under a Creative Commons Attribution 4.0 International License. Read Full License

Version of Record: A version of this preprint was published at Environmental Science and Pollution Research on March 15th, 2022. See the published version at https://doi.org/10.1007/s11356-022-196429 . 
1 Does Agricultural Mechanization Improve Agriculture Environment

2 Efficiency?-Evidence from China's Planting Industry

3 Yingyu Zhu ${ }^{1}$ Yan Zhang ${ }^{1,2}$ Huilan Piao $^{1}$

41 College of Economics and Management, Shenyang Agricultural University, Shenyang 110866, China

52 Institute of Higher Education, Shenyang Agricultural University, Shenyang 110866, China

6 Abstract

7 It has important theoretical value and practical significance to study the impact of agricultural mechanization (AM)

8 on agriculture environment efficiency (AEE), as AM is an important way to improve the level of rural

9 modernization and accelerate the high-quality development of agriculture, while the increase of energy

10 consumption of AM has brought greenhouse gas emissions. Using the panel data of 30 provinces in China from

112001 to 2019, this article adopts stochastic frontier analysis method with output oriented distance function to

12 measure AEE based on net carbon sink, and empirically analyzes the impact of AM on AEE. The empirical analysis

13 finds that the AEE of the whole country and all provinces shows an upward trend with time, and has significant

14 spatial positive autocorrelation characteristics. There is a Kuznets inverted "U" relationship between AM and AEE.

15 Meanwhile, AM has spatial spillover effect and time cumulative effect on AEE, and this basic conclusion is still

16 robust after using instrumental variables, spatial autoregressive model, sub sample regression, changing spatial

17 weight matrix and independent. Further research shows that the effect of AM on AEE depends on the input effect

18 and output effect caused by AM, and the mechanism is mainly reflected in agricultural technology progress,

19 expansion of the scale of agricultural operation, optimization of resource allocation and spatial spillover. Given

20 these findings, the paper adds considerable value to the empirical literature and also provides various policy- and

21 practical implications.

22 Keywords Agricultural mechanization · Net carbon sink · Agriculture environment efficiency $\cdot$ Spatial spillover 23 effect $\cdot$ Temporal cumulative effect $\cdot$ Stochastic frontier analysis $\cdot$ Output oriented distance function

24

25

\section{Introduction}

Promoting agricultural mechanization (AM) is an effective way to improve the level of agricultural modernization and accelerate the high-quality development of agriculture in China at present. Since the cross regional service of agricultural machinery began in 1996 and the large-scale policy subsidy for agricultural machinery began in 2005, advanced and applicable agricultural machinery has become more and more popular and the degree of mechanization has been continuously improved. According to the China Rural Statistical Yearbook, the total power of China's agricultural machinery increased from 552 million $\mathrm{kW}$ in 2001 to 1028 million kW in 2019, of which the number of large and medium-sized tractors surged from 829900 to 4438600 . In 2021, No. 1 central document continued to point out that the whole process AM of main crops should be carried out, and the industrial clusters and industrial chains of AM should be strengthened. 
On the one hand, AM has improved agricultural productivity through technology progress and diffusion (Wang et al. 2016), allocation efficiency optimization (Tang and Wang 2018), planting structure adjustment (Tan and Zheng 2019). On the other hand, the popularization of mechanization, accompanied by energy consumption, emits a large number of greenhouse gases. By 2018, the carbon emissions from energy consumption of agricultural machinery had become the main source of agricultural carbon emissions (Luo et al. 2020). The action plan for the development of agricultural machinery and equipment (2016-2025) proposes that the rate of AM should be increased to more than $75 \%$ in 2025 , so the carbon emission caused by mechanical energy consumption will further increase. Therefore, under the vision of carbon peak and carbon neutralization, it has become a realistic and urgent problem to explore the relationship between AM and agricultural carbon emission and seek the balance between them.

Academic research on China's AM mainly focuses on two aspects. One is to discuss its impact on agricultural production, such as the standardized application of advanced agricultural technology (Chavas and Nauges 2020), the adjustment of agricultural planting structure (Tan and Zheng 2019) and the increase of farmers' income (Choi et al. 2021). The second is the external conditions affecting the development of AM, such as farmland right confirmation (Zhao et al. 2021), the construction of AM service system (Ismael et al. 2018), agricultural infrastructure and the transformation of agricultural machinery demand structure (Ji et al. 2012). As the current main contributor and future potential grower of agricultural carbon emissions, the topic of the relationship between AM and agriculture environment efficiency (AEE) has not been effectively concerned by scholars. Therefore, this paper attempts to study the impact of AM on AEE and logically find out the internal mechanism path, to contribute to the balance between AM development and agricultural carbon emission reduction.

Due to the zero correlation and weak disposability between AM and carbon emission, carbon emission is accompanied by production. Therefore, the key to agricultural carbon emission reduction lies in the improvement of efficiency and the optimization of carbon emission efficiency in the production. The existing literature to measure agricultural carbon emissions mainly has the following perspectives. First, considering carbon emissions purely (Ismael et al. 2018) or taking carbon emissions as undesirable output to calculate AEE (Akbar et al. 2021). However, only considering carbon emissions overemphasizes the negative side of agricultural production and ignores the positive yield and carbon sink of crops. Second, using the net carbon sink (She et al. 2017) based on the dual attributes of both carbon sink and carbon source in agriculture, which ignores the ties between input and output. Third, using the ratio of carbon emissions to agricultural output to measure carbon emission intensity (IPCC 2007). Although the relation between carbon emissions and agricultural output is considered, the correlation between various agricultural inputs is ignored. Based on the analysis above, this paper adopts the stochastic frontier analysis method to obtain the AEE considering environmental factors from the perspective of input-output, which better fits the dual attributes of agriculture, viz. carbon source and carbon sink, to examine China's agricultural carbon emission intensity to correspond to low-carbon and high-quality agricultural development.

The remainder of this article is structured as follows: the "Literature review and mechanism analysis" section 
reviews the related literature and analyzes the mechanism of AM affecting AEE. The "Method and data" section describes the measurement of AEE and the nature of data. Empirical results are presented and analyzed in the "Results and discussion" section, and the "Conclusion" section concludes the article.

\section{Literature review and mechanism analysis}

\section{AEE}

AEE is the real production efficiency considering the cost of resources and environment, which brings pollution emission into traditional agricultural efficiency which only considers resource consumption and agricultural production. Agricultural environmental factors can be distinguished from two dimensions: agricultural non-point source pollution and agricultural carbon emissions. Most studies choose agricultural carbon emissions as undesirable output, such as Ismael et al. (2018) and Akbar et al. (2021). Agriculture has the dual attributes of carbon sink and carbon source, so crop yield, agricultural carbon emission and carbon sink should be included in agricultural output. Considering the same nature of carbon emission and carbon sink, agricultural output can be measured from two aspects, viz. crop yield and net carbon sink. As planting is the main source of agricultural carbon emission, this paper mainly examines the carbon emission of planting, including energy consumption in the production process, the use of chemical agricultural materials, methane emission in the growth process of rice, and the emission of fixed carbon in the soil layer caused by cultivated land and irrigation.

\section{Direct effect of AM on AEE}

From the perspective of input, the fossil energy consumption of agricultural machinery increases carbon emissions, while the improvement of operation accuracy and technology spillover effect brought by AM reduce the unreasonable use of chemical agricultural materials, which leads to the reduction of carbon emissions. Agricultural inputs that bring carbon emissions mainly include mechanical fuel and chemical agricultural materials. On the one hand, the increasing effect of AM on agricultural carbon emission is reflected in energy consumption. The large consumption of fossil fuels increases the carbon emission in the process of crop production, causing the reduction of net carbon sink and negatively affecting the AEE (Jiang et al. 2020). On the other hand, AM alleviates the problem of excessive and inaccurate use of chemical agricultural materials caused by the fragmentation of cultivated land through the division of labor in production. Especially, when fertilization, spraying and irrigation are completed with the help of energy-saving and efficient agricultural machinery, agricultural production will be more efficient and low consumption. As one of the main sources of agricultural carbon emission, the change of chemical agricultural materials application intensity will inevitably lead to the change of carbon emission intensity.

From the perspective of output, with the improvement of AM, the agricultural output capacity is improved, which leads to the increase of agricultural carbon sink and effectively improves the AEE. On the whole, AM is one of the most important factors impacting the grain yield per unit area (Cheng et al. 2007). Crop growth needs to absorb $\mathrm{CO}_{2}$ for photosynthesis to synthesize organic substance, so there is an obvious positive relationship between crop 

of standard carbon to 281 million tons in 2016, and the net carbon sink increased from 529 million tons to 747 million tons, which shows obvious characteristics of agricultural net carbon sink (She et al. 2017).

\section{Relationship between AM and AEE}

To accurately estimate the relationship between $\mathrm{AM}$ and $\mathrm{AEE}$, this paper constructs a mathematical model for analysis. Based on the stochastic frontier model proposed by Battese and Coelli (1992), AEE can be expressed as:

where $A E E_{i t}$ represents AEE of province $\mathrm{i}$ at time $\mathrm{t} ; Y_{i t}$ and $f\left(X_{i t}, \beta\right)$ are the actual output and production frontier, respectively; $v_{i t}$ accounts for stochastic errors. The first derivative of AEE to AM is conducted as follows:

$$
\begin{aligned}
\frac{\partial A E E_{i t}}{\partial X_{i t}^{*}} & =\frac{1}{f\left(X_{i t}, \beta\right) e^{v_{i t}}} \times \frac{\partial Y_{i t}}{\partial X_{i t}^{*}}-\frac{Y_{i t}}{\left[f\left(X_{i t}, \beta\right)\right]^{2} e^{v_{i t}}} \times \frac{\partial f\left(X_{i t}, \beta\right)}{\partial X_{i t}^{*}} \\
& =\frac{1}{f\left(X_{i t}, \beta\right) e^{v_{i t}}} \times \frac{\partial Y_{i t}}{\partial X_{i t}^{*}} \times\left[1-\frac{Y_{i t}}{f\left(X_{i t}, \beta\right)} \times \frac{\partial f\left(X_{i t}, \beta\right)}{\partial Y_{i t}}\right] \\
& =\frac{1}{f\left(X_{i t}, \beta\right) e^{v_{i t}}} \times \frac{\partial Y_{i t}}{\partial X_{i t}^{*}} \times\left[1-\frac{\eta_{F}}{\eta_{Y}}\right]
\end{aligned}
$$

where $X_{i t}^{*}$ refers to AM, $\eta_{F}$ and $\eta_{Y}$ represent the factor output elasticity of frontier production and actual production respectively, and $\eta_{F}<\eta_{Y}$; Moreover, considering the rational assumption of production, the marginal output of AM is positive, viz. $\partial \mathrm{Y}_{i t} / \partial X_{i t}^{*}>0$, then

Eq. (3) indicates that $\mathrm{AM}$ improves AEE. If the rational production hypothesis is relaxed, when the AM investment exceeds a certain degree, $\partial \mathrm{Y}_{i t} / \partial X_{i t}^{*}<0$ will appear, then $\partial A E E_{i t} / \partial X_{i t}^{*}<0$, which means that when the degree of AM is excessive, the AEE begins to decline. Similarly,

$$
\begin{aligned}
\frac{\partial^{2} A E E_{i t}}{\partial^{2} X_{i t}^{*}} & =\frac{1}{f\left(X_{i t}, \beta\right) e^{v_{i t}}} \times \frac{\partial^{2} Y_{i t}}{\partial^{2} X_{i t}^{*}} \times\left[1-\frac{\eta_{F}}{\eta_{Y}}\right]-\left[\frac{1}{f\left(X_{i t}, \beta\right) e^{v_{i t}}} \times \frac{\partial Y_{i t}}{\partial X_{i t}^{*}}\right]^{2} \times\left[1-\frac{\eta_{F}}{\eta_{Y}}\right] \\
& -\frac{Y_{i t}}{\left[f\left(X_{i t}, \beta\right)\right]^{2} e^{v_{i t}}} \times \frac{\partial f\left(X_{i t}, \beta\right)}{\partial X_{i t}^{*}} \times \frac{\partial Y_{i t}}{\partial X_{i t}^{*}} \times\left[1-\frac{\eta_{F}}{\eta_{Y}}\right]
\end{aligned}
$$

119 Considering the law of diminishing marginal return, there is $\partial^{2} Y_{i t} / \partial^{2} X_{i t}^{*}<0$, then

Eq. (5) shows that there is a downward trend in the positive correlation between the degree of AM and AEE. Based on the above analysis, this paper puts forward hypothesis 1: under the condition of rational production, AM improves AEE, but the promotion speed shows a downward trend, which is due to the marginal decline law of factor 
$132 \frac{\partial A E E_{i t}}{\partial X_{j t}^{*}}>0$ $\mathrm{AM}$ and AEE.

input. If the condition of production rationality is relaxed, Kuznets inverted " $U$ " relationship is showed between

Furtherly, this paper estimates the spatial spillover effect of AM on AEE:

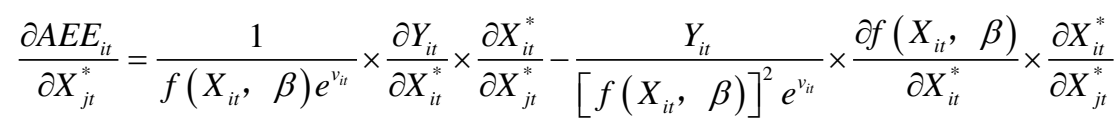

$$
=\frac{1}{f\left(X_{i t}, \beta\right) e^{v_{i t}}} \times \frac{\partial Y_{i t}}{\partial X_{i t}^{*}} \times\left[1-\frac{\eta_{F}}{\eta_{Y}}\right] \times \frac{\partial X_{i t}^{*}}{\partial X_{j t}^{*}}
$$

where $X_{j t}^{*}$ denotes AM in area $\mathrm{j}$ adjacent to area i. Cross regional service of agricultural machinery is developing rapidly all over the country at present, and the service scope and operation fields are expanding continuously, so it can be inferred that $\partial X_{i t}^{*} / \partial X_{j t}^{*}>0$, viz. the improvement of AM in an area could increase the degree of AM in adjacent areas, then

Eq. (7) shows that there is also a positive correlation between AM in adjacent areas and AEE in this region. Based on the above analysis, this paper puts forward hypothesis 2: AM has obvious spatial spillover effect on AEE.

Finally, this paper estimates the cumulative effect of AM on AEE:

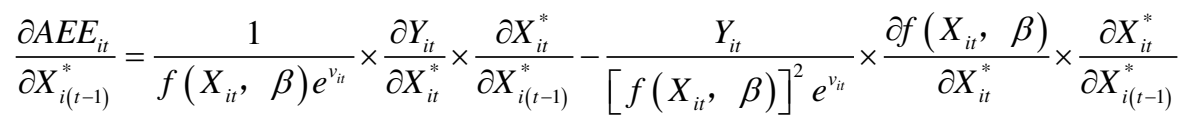

$$
\begin{aligned}
& =\frac{1}{f\left(X_{i t}, \beta\right) e^{v_{i t}}} \times \frac{\partial Y_{i t}}{\partial X_{i t}^{*}} \times\left[1-\frac{\eta_{F}}{\eta_{Y}}\right] \times \frac{\partial X_{i t}^{*}}{\partial X_{i(t-1)}^{*}}
\end{aligned}
$$

As a typical durable investment product, agricultural machinery has a long service life generally, which can meet the demand of agricultural production (Yang et al. 2013). In theory, the machinery investment in the previous year will have a positive impact on it in the next year, so it can be conducted that $\partial X_{i t}^{*} / \partial X_{i(t-1)}^{*}>0$, viz. the improvement of AM in the former year could increase AM degree in the current year, then

$141 \frac{\partial A E E_{i t}}{\partial X_{i(t-1)}^{*}}>0$

Eq. (9) shows that there is a positive correlation between the degree of AM in the former year and the AEE in the current year. Based on the above analysis, this paper puts forward hypothesis 3: AM has obvious time cumulative effect on AEE.

\section{Mechanism of AM on AEE}

First, AEE is improved by AM through technology progress. At present, China's AM technology has become the leading agricultural technology, and the degree of AM which represents the quantity of agricultural machinery and the level of agricultural technology, can directly affect agricultural production efficiency (Qing et al. 2019). 
Agricultural technology progress is an important way to control agricultural energy growth and realize the reduction of agricultural carbon emission (Fei and Lin 2016). First, agricultural technology progress directly reduces carbon emissions per unit of energy consumption by improving the efficiency of traditional energy use. Secondly, agricultural technology progress reduces carbon emissions by changing the traditional factor input structure (Wang and Jiang 2019). Thirdly, agricultural technology progress will indirectly optimize the agricultural energy consumption structure, increase the utilization of new renewable energy, optimize agricultural industrial structure and reduce the proportion of high energy consumption technologies. Finally, AM optimizes the application level and management measures of chemical agricultural materials through experience spillover and information transmission. The optimization of agricultural management measures has a positive effect on emission reduction

158 (Qing et al. 2019). In short, agricultural technology progress could effectively reduce carbon dioxide emissions and improve AEE.

Second, AEE is improved by AM through changing the scale of farming. On the one hand, AM accelerates land circulation, and then changes the scale of farming land. There is a significant negative correlation between the scale of farming land and the amount of agricultural chemical inputs (Wu et al. 2018). The change of chemical agricultural materials intensity will inevitably lead to the change of carbon emission intensity. On the other hand, with the development of AM, the division of labor in production chains makes it possible for farmers to purchase agricultural machinery services. Under the situation of rising labor costs, farmers participate in external division of labor through machinery outsourcing services, which realizes service economies of scale. In particular, for staple food crops, due to the difference in maturity between North and South crops, along with the regional specialization of continuous planting and the marketization of outsourcing services, the spatial layout structure along the latitude further strengthens the cross regional service of agricultural machinery, which is more suitable for the service economies of scale and then transforms the land scale economy into agricultural machinery service scale economy. In short,

171 AM changes the input of chemical agricultural materials by expanding the scale of farming land and realizing service economies of scale, resulting in changes in carbon emission and AEE.

173 In addition, AEE is improved by AM through optimizing resource allocation. The combination of rural labor force, land and other factors will be optimized by the promotion of agricultural machinery. First, the promotion of AM will inevitably lead to the adjustment of the input structure of agricultural factors (Liu et al. 2020). The continuous reduction of the relative price of machinery to labor, results in the decrease of labor input intensity and then the increase of other capital inputs such as chemical fertilizer in agricultural production (Takeshima et al. 2017). The change of the input structure of production factors will affect the change of agricultural carbon emission, resulting in the change of AEE (Yu et al. 2020). Secondly, the promotion of AM will change the planting structure.

180 With the improvement of AM, the planting proportion of non-grain crops declines while the grain crops increases significantly. Compared with cash crops, grain crops generally have less demand for chemical fertilizer. With the increase of the planting proportion of grain crops, the total amount of chemical agricultural materials investment 
may decrease, carbon emissions and AEE will change accordingly.

Finally, AEE is improved by AM through spatial spillover effects. The impact of AM on AEE is carried out under the background of spatial interaction, which has a strong spatial spillover effect (Tang et al. 2021). Agricultural machinery containing agricultural technology has obvious diffusion and spillover, which depends on good technological innovation and technology diffusion, specialized division of labor and cooperation. In terms of geographical status of planting industry, the endowment conditions of agricultural production in adjacent areas are similar, which is easy to form agricultural agglomeration effect and enhance the agricultural industrial network connection. The improvement of AM will not only lead to the change of AEE in the region, but also influence the competition and cooperation interaction with neighboring areas (Cui et al. 2021), and the AEE of neighboring areas will also change.

Based on the above analysis, this article constructs the following impact mechanism framework.

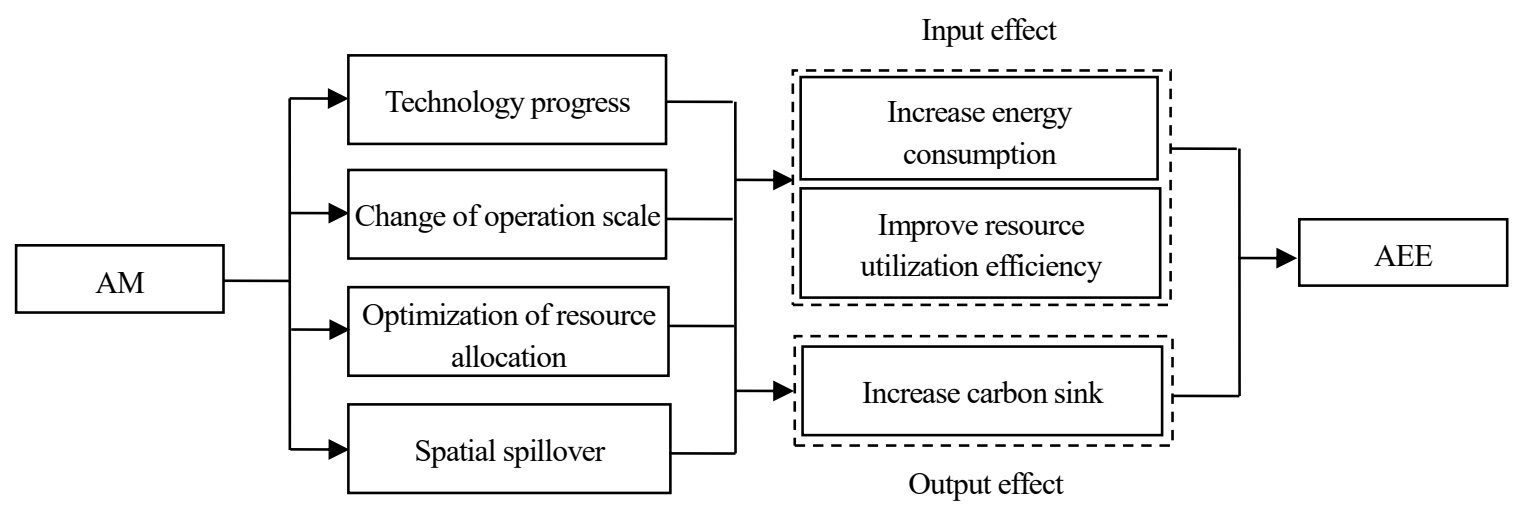

Fig.1 Influence mechanism of AM on AEE

\section{Method and data}

\section{Estimation of AEE}

The methods of measuring AEE mainly include data envelopment analysis (DEA) and stochastic frontier analysis (SFA). When the model setting is reasonable and panel data is used, SFA method will get better estimation effect than DEA method (Gong and sickles, 1992). Compared with DEA method, SFA method can not only explain statistical noise, but also study the traditional hypothesis test, especially for the function hypothesis of production frontier. Measuring AEE involves multi input and multi output technology. Coelli and Perelman (1999) extended SFA method based on output distance function to estimate the parameters of multi output production technology and predict technical efficiency.

To estimate AEE based on the stochastic frontier analysis method of output oriented distance function, we define the planting production technology set $T_{i t}=\left\{\left(X_{i t}, Y_{i t}\right): X_{i t}\right.$ can produce $\left.Y_{i t}\right\}$ and production set 
$P\left(X_{i t}\right)=\left\{Y_{i t}:\left(X_{i t}, Y_{i t}\right) \in T_{i t}\right\}$, where $X_{i t}=\left(X 1_{i t}, X 2_{i t}\right.$ $\left.X 5_{i t}\right)$ is an $1 \times 5$ vector of inputs, which contains machinery, labor, land, chemical fertilizer and diesel oil; and $Y_{i t}=\left(Y 1_{i t}, Y 2_{i t}\right)$ is an $1 \times 2$ vector of outputs, which contains crop product and net carbon sink.

The output oriented distance function is defined as the ratio of the actual output to the frontier output, and output satisfies linear homogeneous property,

$D_{o}\left(X_{i t}, Y_{i t}\right)=\inf \left\{\delta_{i t}:\left(Y_{i t} / \delta_{i t}\right) \in P\left(X_{i t}\right)\right\}$

$$
D_{o}\left(X_{i t}, Y_{i t}\right)=Y 2_{i t} \cdot D_{o}\left(X_{i t}, Y_{i t}^{*}\right)
$$

$$
\text { where } Y_{i t}^{*}=\left(Y 1_{i t}^{*}, 1\right) \text { and } Y 1_{i t}^{*}=Y 1_{i t} / Y 2_{i t} \text {. }
$$

214 After logarithmic transformation and some algebra,

$\ln Y 2_{i t}=\ln D_{o}\left(X_{i t}, Y_{i t}\right)-\ln D_{o}\left(X_{i t}, Y_{i t}^{*}\right)$

In the selection of frontier production function, C-D production function has been widely used in the literature, but it is limited by lack of flexibility, neutral technology progress and constant output elasticity. As the second-order Taylor approximation of any production function, the transcendental logarithmic production function is more flexible in form, and can consider the technology progress, the substitution effect between input factors and the interaction effect of input factors on productivity and efficiency. So, this paper uses the combination of transcendental logarithm function to estimate the stochastic frontier,

$$
\begin{aligned}
\ln Y 2_{i t} & =\alpha_{0}+\sum_{m=1}^{5} \alpha_{m} \ln X \mathrm{~m}_{i t}+\beta_{1} \ln Y 1_{i t}^{*}+\phi t+\frac{1}{2} \sum_{m=1}^{5} \sum_{j=1}^{5} \alpha_{m j} \ln X \mathrm{~m}_{i t} \ln X \mathrm{j}_{i t}+\frac{1}{2} \beta_{11}\left(\ln Y 1_{i t}^{*}\right)^{2} \\
& +\sum_{m=1}^{5} \varphi_{m} \ln X \mathrm{~m}_{i t} \ln Y 1_{i t}^{*}+\frac{1}{2} \tau \mathrm{t}^{2}+\sum_{m=1}^{5} \theta_{m} t \ln X \mathrm{~m}_{i t}+\beta_{t 1} t \ln Y 1_{i t}^{*}-u_{i t}+v_{i t}
\end{aligned}
$$

where $\alpha_{m j}=\alpha_{j m}, m, j=1,2, \ldots \ldots, 5 ; u_{i t}=\ln D_{o}\left(X_{i t}, Y_{i t}\right)$ represents the non-efficiency item of agricultural environment, which is usually assumed to follow a unilateral distribution; $v_{i t}$ is a stochastic error term, including the influence of measurement error and other uncontrollable factors, which is assumed to follow $N\left(0, \sigma_{v}^{2}\right)$ and independent of $u_{i t}$. Eq. (13) is a standard stochastic frontier analysis model, and the unknown parameters can be obtained by maximum likelihood estimation。

\section{Variables and data}

The variables and data used in this study are provincial-level agricultural outputs and inputs of 30 provinces in mainland China from 2001 to 2019 due to the lack of some statistical data of Hong Kong, Macao, Taiwan and Tibet.

231 The data comes from China rural statistical yearbook and China agricultural machinery yearbook. Taking into account the price factor, the variables related to price are deflated according to the price level in 2001.

Input and output variables. This paper follows the traditional literature (Kalirajan et al.1996, Zhou and Zhang 2013, Toma et al. 2015, Gong 2017) in selecting inputs and outputs for the production function. The output variables include gross added value of agricultural output (in thousand CNY) and agricultural net carbon sink (in thousand 
tons of $\mathrm{CO}_{2}$-equivalent). The calculation formula, coefficient of agricultural carbon sink and carbon emission are

237 based on the research of Tian et al. (2014). The main input variables of agricultural production are labor, land,

238 machinery, fertilizer and diesel oil. Labor (in thousands) is measured as the number of employees in the primary

239 industry multiplied by the proportion of the total output value of planting industry in the total output value of $\mathrm{f}$

240 primary industry. Land (in thousand hectares) refers to the sown area reflecting the actual utilization of the cultivated

241 land. Machinery (in thousand kilowatts) is measured by the total power of agricultural machinery multiplied by the

242 proportion of the total output value of planting industry in the total output value of primary industry. Fertilizer (in

243 thousand tons) refers to the sum of the gross weight of nitrogen, phosphate, potash, and complex fertilizers. Diesel

244 oil (in thousand tons) is measured as the diesel consumption of agricultural machinery.

245 Independent variable. This paper adopts the comprehensive mechanization rate of crop cultivation and harvest

246 as the core explanatory variable, which is measured by the weighted average value of machine tillage rate, machine

247 sowing rate and machine yield (the weights are 0.4, 0.3 and 0.3 respectively). Meanwhile, the square term of AM

248 is introduced to examine the possible Kuznets relationship between them.

249 Control variables. The main control variables include: agricultural land management scale, agricultural planting

250 structure, rural human capital, regional economic development level, part-time employment of labor force,

251 production risk and urban-rural income gap. Agricultural land management scale (in hectare per household) is

252 represented by the ratio of cultivated land area to rural households and its square term is introduced to examine the

253 possible threshold of agricultural land scale. Agricultural planting structure is characterized by the ratio of grain

254 sowing area to crop sowing area. Rural human capital (in years) is measured as the average number of years of

255 education of rural population. Regional economic development level (in CNY per person) is represented by per

256 capita GDP. The proportion of wage income of rural residents is selected to represent the part-time employment of

257 labor force. Production risk refers to the ratio of affected area to total sown area of crops. The urban-rural income

258 gap is measured as the ratio of disposable income of urban residents to rural residents. The descriptive statistics of

259 variables are shown in Table 1.

260 Table 1

Descriptive statistics

\begin{tabular}{|c|c|c|c|c|c|c|}
\hline Variable type & Variable & Abbreviation & Mean & Std. Dev. & Min & Max \\
\hline \multirow{2}{*}{$\begin{array}{l}\text { Output } \\
\text { variables }\end{array}$} & Log(Production) & $\mathrm{Y} 1_{\text {it }}$ & 12.583 & 1.064 & 9.723 & 14.147 \\
\hline & Log(Net carbon sink) & $\mathrm{Y} 2_{\mathrm{it}}$ & 10.388 & 1.303 & 6.671 & 12.432 \\
\hline \multirow{5}{*}{$\begin{array}{l}\text { Input } \\
\text { variables }\end{array}$} & $\log ($ Labor $)$ & $\mathrm{X} 1_{\text {it }}$ & 8.123 & 1.143 & 5.037 & 10.000 \\
\hline & Log(Machinery) & $\mathrm{X} 2_{\text {it }}$ & 9.138 & 1.128 & 6.100 & 11.166 \\
\hline & Log(Fertilizer) & $\mathrm{X} 3_{\text {it }}$ & 7.600 & 1.087 & 4.127 & 8.876 \\
\hline & $\log ($ Land $)$ & $\mathrm{X} 4_{\text {it }}$ & 8.188 & 1.085 & 4.484 & 9.609 \\
\hline & Log(Diesel oil) & $\mathrm{X} 5_{\text {it }}$ & 6.013 & 1.039 & 2.890 & 8.491 \\
\hline $\begin{array}{l}\text { Independent } \\
\text { variable }\end{array}$ & Mechanization & $\operatorname{mac}$ & 0.488 & 0.226 & 0.013 & 0.963 \\
\hline Control & Scale & sca & 68.432 & 60.263 & 9.286 & 306.432 \\
\hline
\end{tabular}


10

\begin{tabular}{ccccccc}
\hline \hline variables & Planting structure & pst & 0.651 & 0.129 & 0.328 & 0.971 \\
Human resource & hum & 7.372 & 0.727 & 4.811 & 9.731 \\
Economic development & gdp & 0.011 & 0.006 & 0.003 & 0.033 \\
Part-time employment & ccj & 15.327 & 21.269 & 0.062 & 76.300 \\
Production risk & ris & 0.227 & 0.155 & 0 & 0.936 \\
& Urban-rural income gap & inc & 2.874 & 0.572 & 1.850 & 5.120 \\
\hline
\end{tabular}

\section{Endogenous and instrumental variable}

AM and AEE may have some endogenous problems for two reasons: first, there may be missing variables. Although this paper tries to control a series of characteristic variables related to agriculture environment in the empirical model, such as agricultural planting structure and rural human capital, it is still unable to completely control the missing variables in theory. Second, simultaneity exists between AM and AEE. Provinces with high level of AEE usually own high level of factor endowment, high level of regional development and high relative labor price, which can adapt to the requirements of local agricultural development through large-scale application of mechanized operation to promote the improvement of AM level in this area. Therefore, this paper attempts to find instrumental variable to alleviate the estimation errors caused by possible endogenous problems.

The selection of instrumental variables needs to meet two conditions: one is that the instrumental variables are highly correlated with the random explanatory variables, the other is that the instrumental variables are not correlated with the random error term in the model. From the perspective of supply side, this paper attempts to use highway transportation infrastructure, viz. the ratio of regional grade highway mileage to cultivated land area, as the instrumental variable of AM. Highway transportation infrastructure don't have a direct impact on agricultural output value and net carbon sink, but it can improve the level of AM by improving the road conditions of agricultural machinery operation and reducing traffic costs to affect agricultural production and AEE.

The above analysis shows that highway transportation infrastructure is closely related to AM, however the instrumental variable may still affect the regional AEE through regional economic development, labor and parttime employment and other channels. For the above channels that may affect AEE, this paper correspondingly controls the variables such as regional economic development level and labor force part-time employment status in the econometric equation. If the endogenous variable coefficient does not change significantly, it indirectly indicates that the exclusive constraints are satisfied, so the instrumental variables can avoid affecting AEE through unobserved factors to the greatest extent.

\section{Results and discussion}

\section{Analysis of AEE}

The calculation results of AEE are shown in Table 2. First, Log likelihood $=726.831$, greater than the critical value of mixed chi square distribution, which indicates that the stochastic frontier production function is effective. Secondly, most of the coefficients of the square term and cross term pass the significance test, which shows that the 
289 choice of transcendental logarithm function is more suitable. Thirdly, $\gamma=0.979$, which means that there is an

290 invalid rate term and the invalid rate term has a large disturbance to the deviation.

291 Table 2

Results of stochastic frontier production function model

\begin{tabular}{|c|c|c|c|c|c|}
\hline Variable & Coefficient & Variable & Coefficient & Variable & Coefficient \\
\hline $\ln \left(X 1_{i t}\right)$ & $\begin{array}{c}2.797^{* * *} \\
(0.731)\end{array}$ & $\ln \left(\mathrm{Y} 1_{\text {it }}{ }^{*}\right) * \ln \left(\mathrm{Y} 1_{\text {it }}{ }^{*}\right)$ & $\begin{array}{c}-0.174 * * * \\
(0.032)\end{array}$ & $\ln \left(\mathrm{X} 1_{\mathrm{it}}\right) * \ln \left(\mathrm{Y} 1_{\mathrm{it}}{ }^{*}\right)$ & $\begin{array}{l}-0.088^{*} \\
(0.050)\end{array}$ \\
\hline $\ln \left(X 2_{i t}\right)$ & $\begin{array}{l}-0.594 \\
(0.419)\end{array}$ & $\mathrm{t}^{*} \mathrm{t}$ & $\begin{array}{c}-0.001 * * * \\
(0.000)\end{array}$ & $\ln \left(\mathrm{X} 2_{\mathrm{it}}\right)^{*} \ln \left(\mathrm{Y} 1_{\mathrm{it}}{ }^{*}\right)$ & $\begin{array}{l}-0.050 \\
(0.034)\end{array}$ \\
\hline $\ln \left(X_{3 i t}\right)$ & $\begin{array}{l}0.655 \\
(0.585)\end{array}$ & $\ln \left(\mathrm{X}_{\mathrm{it}}\right) * \ln \left(\mathrm{X} 2_{\mathrm{it}}\right)$ & $\begin{array}{l}-0.030 \\
(0.054)\end{array}$ & $\ln \left(X 3_{\mathrm{it}}\right)^{*} \ln \left(\mathrm{Y} 1_{\mathrm{it}}{ }^{*}\right)$ & $\begin{array}{l}-0.032 \\
(0.049)\end{array}$ \\
\hline $\ln \left(\mathrm{X} 4_{\mathrm{it}}\right)$ & $\begin{array}{c}-2.094 * * \\
(0.923)\end{array}$ & $\ln \left(\mathrm{X} 1_{\mathrm{it}}\right) * \ln \left(\mathrm{X} 3_{\mathrm{it}}\right)$ & $\begin{array}{c}0.204 * * * \\
(0.073)\end{array}$ & $\ln \left(\mathrm{X} 4_{\mathrm{it}}\right) * \ln \left(\mathrm{Y} 1_{\mathrm{it}}{ }^{*}\right)$ & $\begin{array}{c}0.223^{* * *} \\
(0.065)\end{array}$ \\
\hline $\ln \left(X 5_{i t}\right)$ & $\begin{array}{l}1.013 * * \\
(0.404)\end{array}$ & $\ln \left(\mathrm{X}_{\text {it }} * * \ln \left(\mathrm{X} 4_{\mathrm{it}}\right)\right.$ & $\begin{array}{c}-0.609^{* * *} \\
(0.129)\end{array}$ & $\ln \left(\mathrm{X} 5_{\mathrm{it}}\right)^{*} \ln \left(\mathrm{Y} 1_{\mathrm{it}}{ }^{*}\right)$ & $\begin{array}{l}-0.053^{*} \\
(0.028)\end{array}$ \\
\hline $\ln \left(Y 1_{\mathrm{it}}^{*}\right)$ & $\begin{array}{l}-0.088 \\
(0.401)\end{array}$ & $\ln \left(\mathrm{X}_{\mathrm{it}}\right) * \ln \left(\mathrm{X} 5_{\mathrm{it}}\right)$ & $\begin{array}{l}0.036 \\
(0.048)\end{array}$ & $\mathrm{t} * \ln \left(\mathrm{X} 1_{\mathrm{it}}\right)$ & $\begin{array}{c}-0.008^{* *} \\
(0.004)\end{array}$ \\
\hline $\mathrm{t}$ & $\begin{array}{c}-0.098^{* * * *} \\
(0.027)\end{array}$ & $\ln \left(\mathrm{X}_{\mathrm{it}}{ }^{*} \ln \left(\mathrm{X} 3_{\mathrm{it}}\right)\right.$ & $\begin{array}{c}-0.184 * * * \\
(0.063)\end{array}$ & $t * \ln \left(X 2_{i t}\right)$ & $\begin{array}{c}0.013 * * * \\
(0.004)\end{array}$ \\
\hline $\ln \left(X 1_{i t}\right) * \ln \left(X 1_{i t}\right)$ & $\begin{array}{c}0.389^{* * *} \\
(0.098)\end{array}$ & $\ln \left(\mathrm{X} 2_{\mathrm{it}}\right) * \ln \left(\mathrm{X} 4_{\mathrm{it}}\right)$ & $\begin{array}{c}0.282^{* * * *} \\
(0.072)\end{array}$ & $t * \ln \left(X 3_{i t}\right)$ & $\begin{array}{l}0.006 \\
(0.004)\end{array}$ \\
\hline $\ln \left(X 2_{i t}\right) * \ln \left(X 2_{i t}\right)$ & $\begin{array}{l}-0.129 * \\
(0.077\end{array}$ & $\ln \left(X 2_{i t}\right) * \ln \left(X 5_{i t}\right)$ & $\begin{array}{c}0.110^{* * *} \\
(0.037)\end{array}$ & $t * \ln \left(X 4_{i t}\right)$ & $\begin{array}{l}0.002 \\
(0.005)\end{array}$ \\
\hline $\ln \left(\mathrm{X}_{\mathrm{it}}\right) * \ln \left(\mathrm{X}_{\mathrm{it}}\right)$ & $\begin{array}{l}-0.172 \\
(0.121)\end{array}$ & $\ln \left(\mathrm{X} 3_{\mathrm{it}}\right) * \ln \left(\mathrm{X} 4_{\mathrm{it}}\right)$ & $\begin{array}{l}-0.052 \\
(0.097)\end{array}$ & $t * \ln \left(X 5_{i t}\right)$ & $\begin{array}{c}-0.007^{* * * *} \\
(0.002)\end{array}$ \\
\hline $\ln \left(\mathrm{X} 4_{\mathrm{it}}\right) * \ln \left(\mathrm{X} 1_{\mathrm{it}}\right)$ & $\begin{array}{c}0.474^{* * *} \\
(0.178)\end{array}$ & $\ln \left(\mathrm{X} 3_{\mathrm{it}}\right) * \ln \left(\mathrm{X} 5_{\mathrm{it}}\right)$ & $\begin{array}{c}0.274^{* * * *} \\
(0.063)\end{array}$ & $\mathrm{t}^{*} \ln \left(\mathrm{Y} 1_{\mathrm{it}}^{*}\right)$ & $\begin{array}{c}0.012^{* * *} \\
(0.002)\end{array}$ \\
\hline $\operatorname{Ln}\left(X 5_{i t}\right)^{*} \ln \left(X 5_{i t}\right)$ & $\begin{array}{l}-0.071 * \\
(0.042)\end{array}$ & $\ln \left(\mathrm{X} 4_{\mathrm{it}}\right) * \ln \left(\mathrm{X} 5_{\mathrm{it}}\right)$ & $\begin{array}{c}-0.313 * * * \\
(0.080)\end{array}$ & Constant & $\begin{array}{c}7.610^{* * *} \\
(2.697)\end{array}$ \\
\hline$\gamma$ & & & 0.979 & & \\
\hline Log likelihood & & & 726.831 & & \\
\hline Observations & & & 570 & & \\
\hline
\end{tabular}

292 Note: *,*****: statistically significant at $1 \%, 5 \%$, and $10 \%$, respectively; Standard error in parentheses.

293 The nuclear density curve of AEE in 2001, 2005, 2010, 2015 and 2019 is shown in Figure 2. The AEE shows the

294 following dynamic evolution trends: first, the main peak shifts slightly to the right, reflecting the upward trend of 
AEE over time; Secondly, the double peak shape is obvious and the right peak is obviously high, indicating that the AEE shows a trend of two-level differentiation, and most of them are concentrated in the high-efficiency area; Thirdly, the rising trend of the main peak is obvious, representing that the gap of AEE among regions gradually shrinks over time, and the rising degree of the higher-efficiency regions is significantly lower than that of the lowerefficiency regions; Finally, there are great regional differences in the distribution of AEE, showing a certain agglomeration. The higher-efficiency provinces are mainly concentrated in the eastern region, such as Heilongjiang and Jilin province, and the lower-efficiency provinces are mostly in the western region, such as Qinghai and Ningxia province.

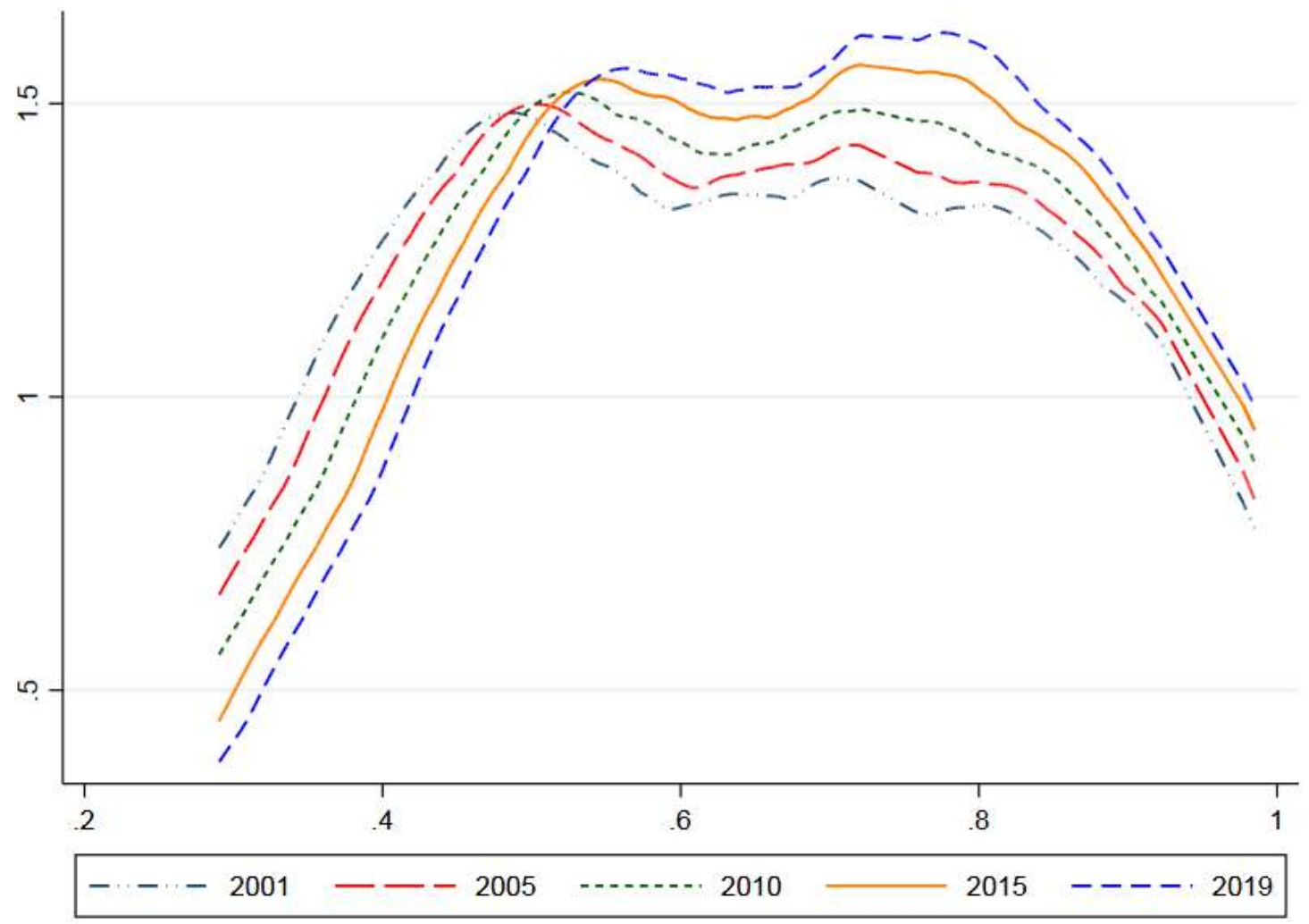

Fig.2 Nuclear density curve of AEE

The global Moran index is introduced to examine whether the AEE has spatial correlation. The results in 2001, 2005, 2010, 2015 and 2019 are shown in Table 3. It can be seen that AEE has a positive spatial correlation, especially when a more accurate geographical distance matrix is used, while the results pass the significance test at the $1 \%$ level. This shows that AEE has significant spatial positive autocorrelation characteristics, viz. the rise of AEE in one region can significantly promote the level of AEE in adjacent regions. From the dynamic evolution trend of Moran index, the spatial correlation gradually strengthens slightly, indicating that the phenomenon of high-value and high-value agglomeration, low-value and low-value agglomeration of AEE increased over time, and the regional difference gradually narrowed. 


\begin{tabular}{c|c|c|c}
\hline \multirow{2}{*}{ Table 3} & \multicolumn{3}{c}{ Global Moran index of AEE } \\
\hline Year & Adjacency matrix & geographical distance matrix & Economic distance matrix \\
\hline 2001 & 0.156 & $0.074^{* * *}$ & $0.126^{*}$ \\
2005 & 0.155 & $0.074^{* * *}$ & $0.127^{*}$ \\
2010 & 0.155 & $0.075^{* * *}$ & $0.127^{*}$ \\
2015 & 0.155 & $0.075^{* * *}$ & $0.128^{*}$ \\
2019 & 0.154 & $0.075^{* * *}$ & $0.129^{*}$ \\
\hline
\end{tabular}

\section{$314 \quad$ Model selection and results}

Relationship between AM and AEE. (1)Model. The basic econometric regression model is set as follows:

$$
A E E_{i t}=\alpha_{0}+\alpha_{1} X_{i t}+\alpha_{2} X_{i t}^{2}+\sum_{j} \beta_{j} Z_{i t j}+\mu_{\mathrm{i}}+\eta_{\mathrm{t}}+\xi_{i t}
$$

where $A E E_{i t}$ represents AEE of province i at time t, $X_{i t}$ and $X_{i t}^{2}$ denote the degree of AM and its square term respectively, $Z_{i t}$ refers to control variables; $\alpha_{0}$ is intercept term, $\alpha_{1}, \alpha_{2}, \beta_{j}$ are the estimation coefficient of each explanatory variable; $\mu_{\mathrm{i}}$ and $\eta_{\mathrm{t}}$ represent the fixed effect of province and time the fixed effect of province $\xi_{i t}$ is a stochastic error term.

321 (2)Results. The basic regression results are shown in Table 4. The OLS regression results without instrumental variables show that AM plays an obvious role in promoting AEE. When the AM level is too high, the inflection point begins to appear, which is 0.395 . The second stage regression results of 2SLS under instrumental variables showed that AM and AEE still shows the same inverted "U" relationship and the coefficient is significant at the level of $1 \%$. The regression results of the first stage show that there is an obvious positive correlation between instrumental variables and AM, whether adding control variables or not, and passes the significance test of $1 \%$, which means that there is a positive correlation between a regional highway infrastructure level and AM. The regression results of the first stage meet the correlation hypothesis of instrumental variables. Among the control variables, there is an inverted "U" relationship between agricultural land scale and AEE, which indicates that there

330 is also a threshold situation of agricultural land scale. Rural human capital also plays an obvious role in promoting

331 AEE. The results provide empirical evidence for hypothesis 1, viz. the degree of AM and AEE show a Kuznets 332 inverted "U" relationship.

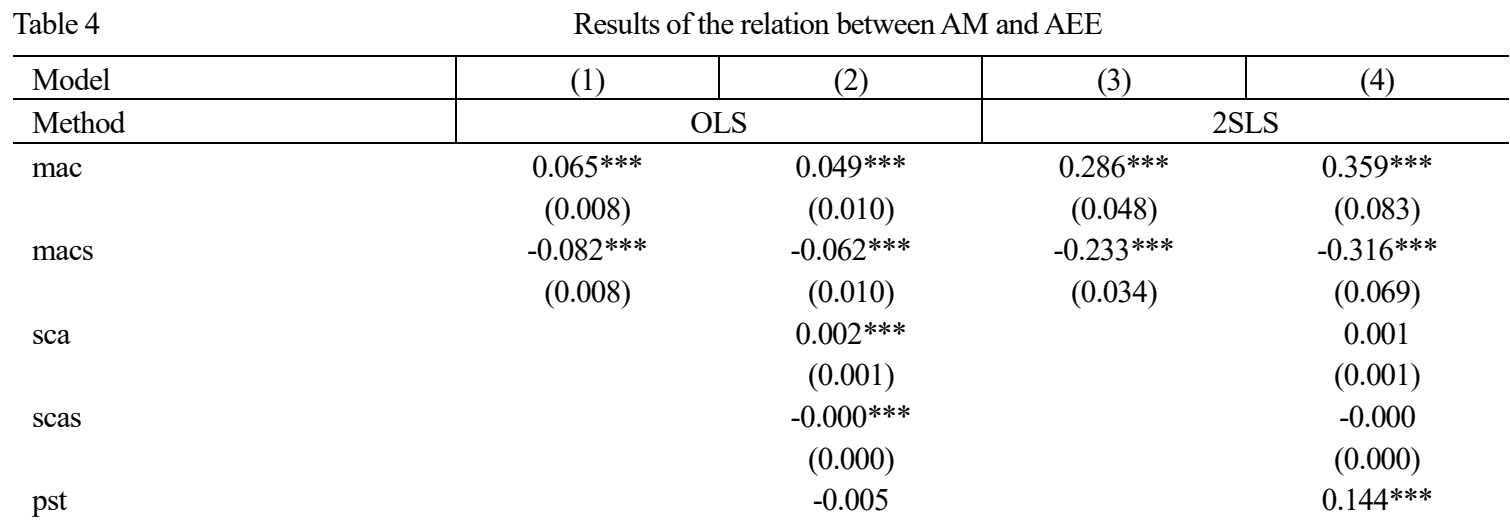




\begin{tabular}{|c|c|c|c|c|}
\hline & & $(0.011)$ & & $(0.043)$ \\
\hline hum & & $\begin{array}{c}0.008 * * * \\
(0.002)\end{array}$ & & $\begin{array}{c}0.006^{* *} \\
(0.003)\end{array}$ \\
\hline gdp & & $\begin{array}{l}-0.495 \\
(0.365)\end{array}$ & & $\begin{array}{l}-0.328 \\
(0.602)\end{array}$ \\
\hline $\operatorname{ccj}$ & & $\begin{array}{c}0.000 \\
(0.000)\end{array}$ & & $\begin{array}{c}0.000 \\
(0.000)\end{array}$ \\
\hline ris & & $\begin{array}{l}-0.001 \\
(0.003)\end{array}$ & & $\begin{array}{l}-0.002 \\
(0.005)\end{array}$ \\
\hline inc & & $\begin{array}{l}-0.004 * \\
(0.002)\end{array}$ & & $\begin{array}{c}0.011^{* *} \\
(0.005)\end{array}$ \\
\hline Fixed province & Yes & Yes & Yes & Yes \\
\hline Fixed year & Yes & Yes & Yes & Yes \\
\hline R-squared & 0.856 & 0.871 & 0.660 & 0.632 \\
\hline Coefficient of IV in the first stage & & & $\begin{array}{c}0.001 * * * \\
(0.000)\end{array}$ & $\begin{array}{c}0.001^{* * *} \\
(0.000)\end{array}$ \\
\hline Value $F$ in the first stage & & & 38.00 & 21.2200 \\
\hline Observations & 570 & 570 & 570 & 570 \\
\hline Provinces & 30 & 30 & 30 & 30 \\
\hline
\end{tabular}

Note: *,**,**: statistically significant at $1 \%, 5 \%$, and $10 \%$, respectively; Standard error in parentheses.

335 Spatial effect analysis. (1)Model. Spatial econometric models contains spatial autocorrelation model, spatial error model and spatial Durbin model. Based on goodness of fit, log likelihood, likelihood ratio and Akaike

337 information criterion, the spatial autocorrelation model (SAR) is selected as the final analysis model.

$338 A E E_{i t}=\alpha_{0}+\tau A E E_{i, t-1}+\rho W \cdot A E E_{i t}+\alpha_{1} X_{i t}+\alpha_{2} X_{i t}^{2}+\sum \phi_{j} Z_{i t j}+\mu_{\mathrm{i}}+\eta_{\mathrm{t}}+\xi_{i t}$

where $\mathrm{W}$ represents the spatial weight matrix, including adjacent space matrix, geographical distance matrix and economic distance matrix, $\tau$ is the first-order lag coefficient of the dependent variable, $\rho$ is the spatial correlation coefficient, $\alpha_{1} 、 \alpha_{2} 、 \phi_{j} 、 \alpha_{w 1} 、 \alpha_{w 2} 、 \phi_{w j}$ are the estimated coefficient of each explanatory variable.

(2)Results. Table 5 reports the results of the spatial regression model of AM on AEE under three different spatial weight matrices. Under the three weight matrices, the spatial lag term of AEE is positive and significant. The results 344 show that in the case of positive spatial spillover effect of AEE, the coefficient values of AM and its square term 345 (macs) are positive and negative respectively and still significant, which further confirms the correctness of 346 hypothesis 1, viz. the Kuznets inverted "U" relationship exists between AM and AEE.

347 Table 5 Results of the spatial relation between AM and AEE

\begin{tabular}{l|c|c|c}
\hline Model & $(1)$ & $(2)$ & $(3)$ \\
\hline \multirow{2}{*}{ mac } & Adjacency matrix & geographical distance matrix & Economic distance matrix \\
& $0.054^{* * *}$ & $0.050^{* * *}$ & $0.048^{* * *}$ \\
macs & $(0.010)$ & $(0.009)$ & $(0.010)$ \\
& $-0.044^{* * *}$ & $-0.052^{* * *}$ & $-0.047^{* * *}$ \\
mac1 & $(0.010)$ & $(0.009)$ & $(0.009)$ \\
& $0.007^{*}$ & 0.001 & 0.003 \\
$\rho$ & $(0.004)$ & $(0.004)$ & $(0.004)$ \\
& $0.367^{* * *}$ & $0.705^{* * *}$ & $0.577^{* * *}$ \\
& $(0.042)$ & $(0.045)$ & $(0.044)$
\end{tabular}




\begin{tabular}{lccc}
\hline R-squared & 0.819 & 0.818 & 0.830 \\
Control Variables & Controlled & Controlled & Controlled \\
Observations & 540 & 540 & 540 \\
Provinces & 30 & 30 & 30 \\
\hline
\end{tabular}

Note: $*, * * * * *$ : statistically significant at $1 \%, 5 \%$, and $10 \%$, respectively; Standard error in parentheses.

349 There are spillover and re feedback effects in spatial panel regression, so direct parameter estimation is easy to 350 cause result error. Only through calculating the direct effect and spatial spillover effect in spatial econometric model 351 and summing up to obtain the total effect, can we comprehensively describe the interactive relationship between 352 dependent variables and independent variables. The results in Table 6 show that AM has a significant spatial 353 spillover effect on AEE, viz. the level of AM in adjacent areas has a Kuznets inverted "U" relationship impact on 354 AEE in this region. Meanwhile, AM is not limited to serving a single region, but also may expand the market space 355 of mechanized operation with the help of the differences in crop maturity. Therefore, mechanized operation not only 356 has a Kuznets inverted "U" relationship with the local AEE, but also has a Kuznets inverted "U" relationship with 357 the AEE of surrounding areas due to the spatial spillover of cross regional operation, which provides evidence to 358 hypothesis 2.

359 To verify the time cumulative effect of AM on AEE, Table 5 and Table 6 also report the regression results of the 360 first-order lag term (mac1) of AM. The regression coefficient, direct effect, spatial spillover effect and total effect 361 are positive, and are significant at the level of $10 \%$ under a more accurate geographical distance spatial matrix. This 362 shows that AM has a time cumulative effect on AEE, which provides evidence for the content of hypothesis 3.

363

\begin{tabular}{|c|c|c|c|c|}
\hline able 6 & & Results of th & tial effect of AM on AEE & \\
\hline \multirow[t]{2}{*}{ Model } & & $(1)$ & $(2)$ & (3) \\
\hline & & Adjacency matrix & geographical distance matrix & Economic distance matrix \\
\hline \multirow{6}{*}{ LR_Direct } & \multirow{2}{*}{ mac } & $0.053^{* * *}$ & $0.056^{* * *}$ & $0.051^{* * *}$ \\
\hline & & $(0.010)$ & $(0.011)$ & $(0.010)$ \\
\hline & \multirow{2}{*}{ macs } & $-0.056^{* * *}$ & $-0.046^{* * *}$ & $-0.051 * * *$ \\
\hline & & $(0.010)$ & $(0.011)$ & $(0.010)$ \\
\hline & \multirow{2}{*}{$\operatorname{mac1}$} & 0.002 & $0.008^{*}$ & 0.004 \\
\hline & & $(0.004)$ & $(0.004)$ & $(0.004)$ \\
\hline \multirow{6}{*}{ LR_Indirect } & \multirow{2}{*}{$\mathrm{mac}$} & $0.118^{* * *}$ & $0.029 * * *$ & $0.062 * * *$ \\
\hline & & $(0.033)$ & $(0.007)$ & $(0.016)$ \\
\hline & \multirow{2}{*}{ macs } & $-0.125^{* * *}$ & $-0.024 * * *$ & $-0.062 * * *$ \\
\hline & & $(0.037)$ & $(0.007)$ & $(0.017)$ \\
\hline & \multirow{2}{*}{ mac1 } & 0.003 & $0.004 *$ & 0.005 \\
\hline & & $(0.009)$ & $(0.002)$ & $(0.005)$ \\
\hline \multirow{6}{*}{ LR_Total } & \multirow{2}{*}{ mac } & $0.172 * * *$ & $0.085^{* * *}$ & $0.113^{* * *}$ \\
\hline & & $(0.041)$ & $(0.017)$ & $(0.024)$ \\
\hline & \multirow{2}{*}{ macs } & $-0.181 * * *$ & $-0.070 * * *$ & $-0.112 * * *$ \\
\hline & & $(0.044)$ & $(0.017)$ & $(0.026)$ \\
\hline & \multirow{2}{*}{ mac1 } & 0.005 & $0.012 *$ & 0.008 \\
\hline & & $(0.013)$ & $(0.006)$ & $(0.009)$ \\
\hline
\end{tabular}


16

Mechanism analysis

This paper studies the transmission mechanism of AM to AEE from the perspectives of technology progress(tec), land scale(siz) and resource allocation(all). Technology progress is represented by the total power of machinery per unit area, land scale is measured as the ratio of cultivated land area to planting population and resource allocation is characterized by the ratio of fertilizer application per unit area to labor input.

According to the test method of Baron and Kenny (1986), the following verification steps are set: (1) regression between $\mathrm{AM}$ and mediator. If the regression coefficient is significant, it indicates that $\mathrm{AM}$ has an impact on mediator. (2) If the above results are true, the $\mathrm{AM}$ and mediator are regressed with the $\mathrm{AEE}$ at the same time. If the regression coefficient of AM decreases or becomes insignificant, it indicates that the impact of AM on AEE comes partly or entirely from the transmission of the mediator. Table 7 reports the results of the mediation effect test model. Models (1), (2) and (3) show the regression results of the first step. The regression coefficients are positive and all pass the significance test of 5\%, indicating that the popularization of AM has significantly improved the level of agricultural technology, expanded the scale of agricultural management and improved the factor allocation structure. The other models show the regression results of the second step, which shows that after adding the variables of technology progress, land scale and resource allocation, the impact coefficient of AM on AEE decreases, but the significance of the coefficient does not change significantly. This shows that the three mediator selected in this paper play a partial intermediary role. At the same time, it also shows that AM is not only used for AEE by improving technical level, expanding land scale and improving resource allocation, but also has a direct effect on AEE.

\begin{tabular}{l|c|c|c|c|c|c|c|c}
\hline Model & $(1)$ & $(2)$ & $(3)$ & $(4)$ & $(5)$ & $(6)$ & $(7)$ & $(8)$ \\
\hline Dependent variable & tec & siz & all & AEE & AEE & AEE & AEE & AEE \\
\hline mac & $1.100^{* * *}$ & $3.715^{* *}$ & $0.783^{* * *}$ & $0.049^{* * *}$ & $0.030^{* * *}$ & $0.043^{* * *}$ & $0.033^{* * *}$ & $0.027^{* * *}$ \\
& $(0.083)$ & $(1.492)$ & $(0.079)$ & $(0.010)$ & $(0.006)$ & $(0.005)$ & $(0.006)$ & $(0.006)$ \\
tec & & & & & $0.009 * * *$ & & & $0.009^{* * *}$ \\
& & & & & $(0.003)$ & & & $(0.003)$ \\
siz & & & & & & $0.002^{* * *}$ & & $0.001^{* * *}$ \\
& & & & & & $(0.000)$ & & $(0.000)$ \\
all & & & & & & & $0.008^{* * *}$ & $0.011^{* * *}$ \\
& & & & & & & $(0.003)$ & $(0.003)$ \\
Control variable & Controlled & Controlled & Controlled & Controlled & Controlled & Controlled & Controlled & Controlled \\
Fixed province & Yes & Yes & Yes & Yes & Yes & Yes & Yes & Yes \\
Fixed year & Yes & Yes & Yes & Yes & Yes & Yes & Yes & Yes \\
R-squared & 0.729 & 0.168 & 0.670 & 0.871 & 0.809 & 0.812 & 0.808 & 0.821 \\
Observations & 570 & 570 & 570 & 570 & 570 & 570 & 570 & 570 \\
Provinces & 30 & 30 & 30 & 30 & 30 & 30 & 30 & 30 \\
\hline
\end{tabular}

Note: $* * *, * * *$ : statistically significant at $1 \%, 5 \%$, and $10 \%$, respectively; Standard error in parentheses.

Sub-samples regression. To further verify the relationship between the level of AM and AEE, the samples are 
Liaoning and Jilin, which have a relatively high level of AM. The regression results of spatial autocorrelation model of geographical distance spatial weight matrix are reported in models (1) and (2) in Table 8. In the main grain producing areas, AM has significant direct effect, spatial spillover effect and total effect on AEE, and the coefficients are greater than the regression data in Table 5, which shows that in the main grain producing areas, the direct effect, spatial spillover effect and total effect of AM on AEE are more obvious. The coefficient of the quadratic term of mechanization is significantly negative, indicating that the Kuznets inverted "U" relationship between AM and AEE is still valid in the main grain producing areas. The direct effect, indirect effect and total effect of the first-order lag term of AM are positive, but not significant at the level of $10 \%$, which indicates that AM has a time cumulative effect on AEE, but not obvious. In the main non grain producing areas, the direct effect, spatial spillover effect and

397 total effect of AM on AEE are only significant at the level of $10 \%$, and the coefficients are lower than the regression

398 data of the main grain producing areas, which shows that compared with the main grain producing areas, the impact 399 of AM on AEE in the main non grain producing areas is weaker.

400 Table $8 \quad$ Results of robust analysis

\begin{tabular}{|c|c|c|c|c|c|}
\hline Model & & $(1)$ & $(2)$ & (3) & (4) \\
\hline & & $\begin{array}{c}\text { Main grain } \\
\text { producing areas }\end{array}$ & $\begin{array}{c}\text { Non-grain } \\
\text { producing areas }\end{array}$ & $\begin{array}{c}\text { Navigation } \\
\text { distance matrix }\end{array}$ & $\begin{array}{c}\text { Replace } \\
\text { independent variable }\end{array}$ \\
\hline \multirow{6}{*}{ LR_Direct } & \multirow{2}{*}{$\operatorname{mac}$} & $0.087 * * *$ & $0.028^{*}$ & $0.053^{* * *}$ & $0.039^{* *}$ \\
\hline & & $(0.014)$ & $(0.015)$ & $(0.010)$ & $(0.019)$ \\
\hline & \multirow{2}{*}{ macs } & $-0.073 * * *$ & -0.019 & $-0.056^{* * *}$ & $-0.055^{* *}$ \\
\hline & & $(0.013)$ & $(0.017)$ & $(0.010)$ & $(0.022)$ \\
\hline & \multirow{2}{*}{ mac1 } & 0.005 & 0.005 & 0.002 & 0.007 \\
\hline & & $(0.004)$ & $(0.006)$ & $(0.004)$ & $(0.006)$ \\
\hline \multirow{6}{*}{ LR_Indirect } & \multirow{2}{*}{ mac } & $0.125^{* * *}$ & $0.044 *$ & $0.125^{* * *}$ & $0.072 * *$ \\
\hline & & $(0.038)$ & $(0.026)$ & $(0.036)$ & $(0.037)$ \\
\hline & \multirow{2}{*}{ macs } & $-0.105^{* * *}$ & -0.030 & $-0.133 * * *$ & $-0.105^{* *}$ \\
\hline & & $(0.035)$ & $(0.028)$ & $(0.040)$ & $(0.044)$ \\
\hline & \multirow{2}{*}{ mac1 } & 0.008 & 0.008 & 0.003 & 0.013 \\
\hline & & $(0.007)$ & $(0.010)$ & $(0.009)$ & $(0.011)$ \\
\hline \multirow{6}{*}{ LR_Total } & \multirow{2}{*}{$\operatorname{mac}$} & $0.212 * * *$ & $0.072 *$ & $0.178^{* * *}$ & $0.111 * *$ \\
\hline & & $(0.047)$ & $(0.040)$ & $(0.043)$ & $(0.055)$ \\
\hline & \multirow{2}{*}{ macs } & $-0.179 * * *$ & -0.048 & $-0.189 * * *$ & $-0.160 * *$ \\
\hline & & $(0.044)$ & $(0.044)$ & $(0.047)$ & $(0.063)$ \\
\hline & \multirow{2}{*}{ mac1 } & 0.013 & 0.013 & 0.005 & 0.021 \\
\hline & & $(0.011)$ & $(0.016)$ & $(0.013)$ & $(0.017)$ \\
\hline \multirow[b]{2}{*}{$\rho$} & & $0.620 * * *$ & $0.637 * * *$ & $0.719 * * *$ & $0.675 * * *$ \\
\hline & & $(0.065)$ & $(0.053)$ & $(0.044)$ & $(0.046)$ \\
\hline R-squared & & 0.837 & 0.854 & 0.818 & 0.813 \\
\hline Control variables & & Controlled & Controlled & Controlled & Controlled \\
\hline Observations & & 234 & 306 & 540 & 540 \\
\hline Provinces & & 13 & 17 & 30 & 30 \\
\hline
\end{tabular}

402 Replace the spatial weight matrix. The traffic convenience among different regions will greatly affect the 
realization of cross regional operation of agricultural machinery. In order to avoid errors caused by straight-line distance, this paper selects the reciprocal of the traffic distance between provincial capitals to construct the spatial weight matrix of navigation distance, and the traffic distance is queried by Google map. The regression results are shown in model (3) in Table 8. It can be seen that the effect of AM on AEE is very significant and robust, especially the spatial spillover effect is more obvious, which may be caused by that the cross regional operation service of machinery depends more on highway transportation facilities(Teruel and Kuroda 2005). The improvement of highway infrastructure can facilitate the cross regional operation of agricultural machinery and promote the full flow and rational allocation of machinery among regions (Mottaleb et al. 2016).

Replace the core independent variable. To verify the reliability of the above analysis, this article further replaces the core independent variable to test the robustness. The total mechanical power per unit area, viz. the ratio of total mechanical power to crop sowing area, is used as the alternative variable of the core explanatory variable. The regression results, which are shown in model (4) in Table 8, presents that the direct impact, spatial spillover effect and total effect of AM on AEE were significantly positive; The coefficient of AM quadratic term is significantly negative, indicating that there is a Kuznets inverted "U" relationship with AEE; Although the three

417 effects of mechanized first-order lag term did not pass the $10 \%$ significance level test, the results were still positive.

418 This shows that after the reconstruction of the core independent variable, the estimation result of the impact of AM on AEE is still robust. The above robustness analysis again provides empirical support for the assumptions proposed in this paper.

\section{Conclusion}

422 This paper selects the panel data of 30 provinces in China from 2001 to 2019, uses the stochastic frontier analysis method of output oriented distance function to measure the AEE based on net carbon sink for the first time, and 424 further discusses its dynamic evolution characteristics; Then, the direct effect, spatial spillover effect and time 425 cumulative effect of AM on AEE is analyzed by using instrumental variable method and spatial econometric method. 426 The main conclusions drawn from the paper are as follows: (1) The AEE of the whole country and all provinces 427 shows an upward trend over time, and the gradient difference between regions tends to converge gradually. The rising speed of AEE in high efficiency areas is significantly lower than that in low efficiency areas and the

429 distribution of AEE has great regional differences, which has significant spatial positive autocorrelation 430 characteristics and gradually strengthens slightly, showing a certain degree of agglomeration. (2) There is a Kuznets 431 inverted "U" relationship between AM and AEE. AM has spatial spillover effect on AEE, viz. the level of AM in adjacent areas has a Kuznets inverted "U" relationship on AEE in this area. AM has a time cumulative effect on

433 AEE, and the former AM investment is conducive to the improvement of AEE in the current period. (3) The 434 relationship between AM and AEE depends on the input effect and output effect caused by AM. The mechanism path is mainly reflected in agricultural technology progress, expansion of land scale and service scale, optimization 
of resource allocation and spatial spillover. Advanced agricultural technology and management measures can improve energy efficiency and optimize energy consumption structure. The appropriate operation scale is conducive to the reduction of chemical agricultural materials, the improvement of factor use efficiency and the realization of economies of scale. Rational resource allocation is the full guarantee for the maximum role of agricultural input resources such as labor, land and chemical fertilizer. The agricultural agglomeration in the geographical position of agricultural industry and the difference of crop maturity at different latitudes make the cross regional service of agricultural machinery more common, resulting in the spatial spillover effect of AM.

Given the above evidence and arguments, some policy implications can be drawn as follows. First, policymakers should strengthen information fusion and regional coordination and cooperation to realize the rational flow and scientific allocation of agricultural machinery resources among regions, which gives full play to the positive spatial spillover effect of AM and ensures that the positive externality of AM is highlighted. The second is to guide the centralized transfer of land and the regional agglomeration of crop planting along the latitudinal differential layout, and strive to realize the land scale economy and service scale economy of agricultural production, which is conducive to the cultivation of agricultural machinery service market and the introduction of small-scale agricultural production into the development track of modern agriculture. The third measurement is to increase investment in highway transportation infrastructure appropriately and improve the traffic and operation conditions of agricultural machinery effectively to lay a solid foundation for comprehensively promoting AM.

Author contribution Zhu developed the design of the manuscript and prepared the draft manuscript. Zhang designed the final manuscript structure and supervised the final version of the manuscript. Piao reviewed the scientific literature and prepared the data and figures.

Funding This work is supported by the Science Foundation of Ministry of Education of China (grant number 19YJA880083), National Natural Science Foundation of China (grant number 71703106), and China Postdoctoral Science Foundation (grant number 2018M631823).

Data availability The datasets used and/or analyzed during the current study are available from the corresponding author on reasonable request.

461

\section{Declarations}

Ethics approval Not applicable.

Consent to participate Not applicable.

Consent for publication Not applicable.

Conflict of interest The authors declare no competing interests.

\section{References}

Akbar U, Li Q L, Akmal M A et al. (2021) Nexus between agro-ecological efficiency and carbon emission transfer: evidence 
Baron RM, Kenny DA(1986) The moderator-mediator variable distinction in social psychological research: conceptual, strategic, and statistical considerations. J Pers Soc Psychol 51:1173-82. https://doi.org/10.1037/0022-3514.51.6.1173

Battese G E, Coelli T J (1992) Frontier production functions, technical efficiency and panel data: With application to paddy farmers in India. J Product Anal 3: 153-169. https://doi.org/10.1007/bf00158774

Chavas J P, Nauges C (2020) Uncertainty, learning and technology adoption in agriculture. Appl Econ Perspect Policy 42: 42-53. https://doi.org/10.1002/aepp.13003

Cheng Y, Zhang P, Zhang H (2007) Variation character of grain yield per unit area in main grain-producing area of Northeast China. Chin. Geograph.Sc 17: 110-116. https://doi.org/10.1007/s11769-007-0110-1

Choi K S, Labhsetwar V K. (2021) Sustainable agricultural growth for rural development in Asia: a review. Irrig. and Drain 70: 470-478. https://doi.org/10.1002/ird.2494

Coelli T J, Perelman S (1999) A comparison of parametric and non-parametric distance functions: With application to European railways. Eur J Oper Res 117: 326-339. https://doi.org/10.1016/s0377-2217(98)00271-9

Cui Y, Khan S U, Deng Y, Zhao M, Hou M (2021) Environmental improvement value of agricultural carbon reduction and its spatiotemporal dynamic evolution: Evidence from China. Sci Total Environ 754: 142170. https://doi.org/10.1016/j.scitotenv.2020.142170

Fei R, Lin B (2016) Energy efficiency and production technology heterogeneity in China's agricultural sector: A meta-frontier approach. Technol Forecast Soc Change 109: 25-34. https://doi.org/10.1016/j.techfore.2016.05.012.

Gong B (2018) Agricultural reforms and production in China: Changes in provincial production function and productivity in 1978-2015. J Dev Econ 132: 18-31. https://doi.org/10.1016/j.jdeveco.2017.12.005

Gong B, Sickles R C (1992) Finite sample evidence on the performance of stochastic frontiers and data envelopment analysis using panel data. J Econ 51: 259-284. https://doi.org/10.1016/0304-4076(92)90038-s

Ismael M, Srouji F, Boutabba M A (2018) Agricultural technologies and carbon emissions: evidence from Jordanian economy. Environ Sci Pollut Res 25:10867-10877. https://doi.org/10.1007/s11356-018-1327-5

Ji Y, Yu X, Zhong F (2012) Machinery investment decision and off-farm employment in rural China. China Econ Rev 23: 7180.https://doi.org/10.1016/j.chieco.2011.08.001

Jiang M, Hu X, Joseph Chunga, Lin Z, Fei R (2020) Does the popularization of agricultural mechanization improve energyenvironment performance in China's agricultural sector?. J Cleaner Prod 276: 124210. https://doi.org/10.1016/j.jclepro.2020.124210

Luo F, Guo Y, Yao M, Cai W, Wang M, Wei W (2020) Carbon emissions and driving forces of China's power sector: Input-output model based on the disaggregated power sector. J Cleaner Prod 268: 121925. https://doi.org/10.1016/j.jclepro.2020.121925

499 Kalirajan K, Obwona M, Zhao S (1996) A decomposition of total factor productivity growth: The case of Chinese agricultural growth before and after reforms. Am J Agric Econ 78: 331-338. https://doi.org/10.2307/1243706 
recent 40 years. Land Use Policy 97: 104794. https://doi.org/10.1016/j.landusepol.2020.104794

Mottaleb K A, Krupnik T J, Erenstein O (2016) Factors associated with small-scale agricultural machinery adoption in Bangladesh: Census findings. J Rural Stud 46: 155-168.https://doi.org/10.1016/j.jrurstud.2016.06.012

Qing Y, Chen M, Sheng Y, Huang J (2019) Mechanization services, farm productivity and institutional innovation in China. China Agric Econ Review 11: 536-554. https://doi.org/10.1108/CAER-12-2018-0244

She W, Wu Y, Huang H, Chen Zh, Cui G, Zheng H, Guan C, Chen F (2017) Integrative analysis of carbon structure and carbon sink function for major crop production in China's typical agriculture regions. J Cleaner Prod 162: 702-708. https://doi.org/10.1016/j.jclepro.2017.05.108

Tan M, Zheng L (2019) Increase in economic efficiency of water use caused by crop structure adjustment in arid areas. J Environ Manag 230: 386-391. https://doi.org/10.1016/j.jenvman.2018.09.060

Tang L, Wang D (2018) Optimization of county-level land resource allocation through the improvement of allocation efficiency from the perspective of sustainable development. Int J Environ Res Public Health 15: 2638. https://doi.org/10.3390/ijerph15122638

Tang Y, Lu X, Yi J, Wang H, Zhang X, Zheng W (2021) Evaluating the spatial spillover effect of farmland use transition on grain production - An empirical study in Hubei Province, China. Ecol Indic 125: 107478. https://doi.org/10.1016/j.ecolind.2021.107478

Takeshima H, Adhikari R P, Shivakoti S, Kaphle B D, Kumar A (2017) Heterogeneous returns to chemical fertilizer at the intensive margins: Insights from Nepal. Food Policy 69: 97-109. https://doi.org/10.1016/j.foodpol.2017.03.007

Toma P, Miglietta P P, Zurlini G, Valente D, Petrosillo I (2017) A non-parametric bootstrap-data envelopment analysis approach for environmental policy planning and management of agricultural efficiency in EU countries. Ecol Indic 83: 132143.https://doi.org/10.1016/j.ecolind.2017.07.049

Teruel R G, Kuroda Y (2005) Public infrastructure and productivity growth in Philippine agriculture, 1974-2000. J Asian Econ 16:555-576. https://doi.org/10.1016/j.asieco.2005.04.011.

Tian Y, Zhang J, He Y (2014) Research on spatial-temporal characteristics and driving factor of agricultural carbon emissions in China. J Int Agric 13: 1393-1403. https://doi.org/10.1016/S2095-3119(13)60624-3.

Wang Q, Jiang R (2019) Is China's economic growth decoupled from carbon emissions?, J Cleaner Prod 225: 1194-1208. https://doi.org/10.1016/j.jclepro.2019.03.301.

Wang X, Yamauchi F, Huang J (2016) Rising wages, mechanization, and the substitution between capital and labor: Evidence from small scale farm system in China. Agric econ 47: 309-317. https://doi.org/10.1111/agec.12231

Wu Y, Xi X, Tang X et al. (2018) Policy distortions, farm size, and the overuse of agricultural chemicals in China. Proc Natl Acad Sci U S A. 115: 7010-7015. https://doi.org/10.1073/pnas.1806645115

533 Yang J, Huang Z, Zhang X, Reardon T (2013) The Rapid Rise of Cross-Regional agricultural mechanization Services in China. 
22

536

537

538

539

540
An input-output perspective. J Cleaner Prod 276: 124169. https://doi.org/10.1016/j.jclepro.2020.124169

Zhao Q, Bao HXH, Zhang Zh (2021) Off-farm employment and agricultural land use efficiency in China. Land Use Policy 101: 105097. https://doi.org/10.1016/j.landusepol.2020.105097

Zhou L, Zhang H (2013) Productivity growth in China's agriculture during 1985-2010. J. Integr. Agric. 12: 1896-1904. https://doi.org/10.1016/S2095-3119(13)60598-5 


\section{Supplementary Files}

This is a list of supplementary files associated with this preprint. Click to download.

- Appendix.docx 